Check for updates

Cite this: RSC Adv., 2018, 8, 5362

Received 22nd December 2017 Accepted 24th January 2018

DOI: $10.1039 / c 7 r a 13588 b$

rsc.li/rsc-advances

\section{Effects of electrochemical properties of ferrocenylpyrazolylnickel(II) and palladium(II) compounds on their catalytic activities in ethylene oligomerisation reactions $\dagger$}

\begin{abstract}
Collins Obuah, (D) *ab Michael K. Ainooson ${ }^{\mathrm{ab}}$ and James Darkwa ${ }^{\mathrm{a}}$
Palladium complexes of ferrocenylpyrazolylpyridine and ferrocenylpyrazolylamine were synthesised and screened as pre-catalysts (1-4) for olefin polymerisation. The pre-catalysts 1-4 on activation with $\mathrm{EtAlCl}$ in the presence of ethylene with chlorobenzene or hexane as solvent were highly active with 1 being the most active, with an activity of $360 \mathrm{~kg} \mathrm{~mol} \mathrm{Pd}^{-1} \mathrm{~h}^{-1}$. The major product from the reaction was 1-butene and high carbon content oligomers. The molecular weight $(\mathrm{m} / \mathrm{z})$ of the high carbon content oligomers is as high as 623.0. When toluene is used as solvent, the products obtained were ethyltoluene and butyltoluene and 1-butene. The electronic properties of the ligands (L1-L7) and complexes (1-10) were determined by cyclic voltammetry (CV) and molecular modelling. The CV results show that the ferrocenyl is easily oxidized upon the introduction of pyrazolyl derivatives, the process is quasireversible. However, complexation of the ligands with palladium or nickel results in difficulty in oxidizing the ferrocenyl moiety. This is an indication of the electrophilic nature of both the palladium and nickel centres. The mechanism of the oxidation was observed to be diffusion-controlled and is independent of scan rate. Molecular modelling experiments show that nickel and palladium complexes have lower HOMO-LUMO gaps and high global descriptors, an indication of a highly electrophilic metal centre. A plot of the electrophilicity indices of the pre-catalysts against yield of the oligomers show a linear correlation, an indication that the electrophilicity of the metal centre plays an important role in the activity of these pre-catalysts.
\end{abstract}

\section{Introduction}

Ethylene is the cheapest and most widely produced organic compound in the world,,$^{1,2}$ and is also an abundant feedstock for the manufacturing of value-added products including linear $\alpha$ olefins (LAOs), a class of commodity chemicals that are used in industries such as synthetic polymers, detergents, plasticizers, and lubricants, and have a global demand of over four million tons per year. ${ }^{3}$ The synthesis of these commodity chemicals involves the use of suitable catalysts. The catalyst has to be finetuned for high activities. Fine-tuning of the catalyst involves the control of the electrons in the catalytic system through ligand design.

The synthesis of functionalised ferrocene is of great importance in the field of organometallic chemistry, ${ }^{4}$ this can be attributed to the unique properties of ferrocene and how

${ }^{a}$ Department of Chemistry, University of Johannesburg, Auckland Park Kingsway Campus, Auckland Park 2006, Johannesburg, South Africa

${ }^{b}$ Department of Chemistry, University of Ghana, Legon, Accra, Ghana. E-mail: cobuah@ug.edu.gh

$\dagger$ Electronic supplementary information (ESI) available. See DOI: 10.1039/c7ra13588b functional groups attached changes the chemistry of ferrocene. Due to the robustness of ferrocene, many applications for its use exist, including its use as redox-active component in homoand heterometallic transition metal complexes. ${ }^{4}$ Ferrocene and its derivatives have been used as molecular sensors, ${ }^{5}$ in energy transfer processes ${ }^{6}$ and as catalysts in various chemical reactions $^{7}$ because of their reversible electrochemical nature. The redox reaction between the ferrocene and ferrocenium ion $\left(\mathrm{Fe}^{\mathrm{II}} /\right.$ $\mathrm{Fe}^{\mathrm{III}}$ ) is a fast and reversible one electron transfer process. This is one of the vital properties of ferrocene and its derivatives. Scientists have taken advantage of this property to focus on the electronic and communication properties in these compounds ${ }^{8}$ through electrochemical studies using techniques such as cyclic voltammetry $(\mathrm{CV}) .{ }^{9,4 b} \mathrm{CV}$ is a very useful electroanalytical technique for compounds containing transition metal centres that may take on several different oxidation states. The CV experiment using the ferrocene as proxy can provide important information about the electron density of transition metal centres in a compound as well as the compound's stability under the experimental conditions employed.

Computational modelling, on the other hand, is another technique that can be used to predict the electronic nature of 
compounds. Recent developments in the area of olefin oligomerisation and polymerisation catalysis using group 10 transition metal catalysts, mainly nickel(II) and palladium(II) catalysts, have shown that the electronic nature of the catalysts is crucial. ${ }^{10}$ To obtain the desirable catalysts requires not only synthetic skills but also an understanding of all kinds of factors influencing the fundamental steps of olefin oligomerisation and polymerisation reactions. ${ }^{11}$ There are numerous articles dealing with polymerisation catalysts of late-transition metals with $\mathrm{N}^{\wedge} \mathrm{O}$ or $\mathrm{N}^{\wedge} \mathrm{N}$ ligand systems. The more established $\mathrm{N}^{\wedge} \mathrm{N}$ catalysts have been the subjects of numerous mechanistic studies based on experimental and theoretical techniques. ${ }^{12}$ The catalytic activity of the transition metal complex is relies more on the electronic configuration of the catalyst in the ground state, especially the charge density. Möhring et al. ${ }^{13}$ have shown that the electronic effect could contribute as much as $80 \%$ of the change in the polymerisation activities. This is by studying the influence of steric and electronic effect of ligands on the catalytic activity of $(\mathrm{CpR})_{2} \mathrm{ZrCl}_{2}$ /ethylaluminoxane. Guo et al. have also shown that metallocene catalyst's activities increase with the reducing charge density ${ }^{14}$ while the catalytic activities of $\alpha$-diimine nickel(II) complexes increase with increase charge density. ${ }^{15}$ Other report using Brookhart's type catalysts have demonstrated through theoretical mechanistic studies using quantum mechanics the importance of the conformation of the substituted on the catalysts and the electrophilicity of the central metal toward the activity of the catalysts. ${ }^{16} \mathrm{~A}$ part from theoretical and experimental evidence, other analytical methods to determine the electronic properties of catalysts have not been extensively investigated.

In view of the importance of electronic properties on catalysts on activity, this report deals with two simple analytical methods (electrochemical and computational modelling) to study the electronics of ferrocenylpyrazolyl nickel(II) and palladium(II) complexes. The ferrocene in the complexes is to service as a probe for the electrochemical studies using CV to indirectly determine the electrophilicity of the metal centre of the catalyst and relate it to the activity of the catalyst towards ethylene oligomerisation and polymerisation reactions.

\section{Experimental section}

\subsection{Materials and instruments}

Compounds were synthesised using standard Schlenk techniques under $\mathrm{N}_{2}$. Organic solvents such as $N, N$-dimethyl formamide (DMF) were dried over $\mathrm{CaH}_{2}$. Hexane over Na lamps while tetrahydrofuran (THF) was dried over Na with benzophenone as indicator. Compounds L1-L7 and 1-10 were synthesised according to literature procedure. ${ }^{17}$ Tetra- $n$-butylammoniumtetrafluoroborate $\left(\left[{ }^{t} \mathrm{BuN}\right]\left[\mathrm{BF}_{4}\right]\right)$ was purchased from Sigma Aldrich and used as received. All electrochemical experiments were performed using Autolab potentiostat PGSTAT 302 (Eco Chemie, Utrecht, The Netherlands) driven by the general purpose Electrochemical System data processing software (GPES, version 4.9). Infrared (IR) spectra of complexes were recorded on a Bruker Tensor 27 equipped with a diamond ATR. Elemental analyses were performed on a Vario elementar III microcube CHNS analyzer. The ESI-MS spectra were recorded on a Waters API Qualtro micro spectrophotometer. NMR spectra were recorded on a Bruker $400 \mathrm{MHz}$ instrument $\left({ }^{1} \mathrm{H}\right.$ at $400 \mathrm{MHz}$ and ${ }^{13} \mathrm{C}\left\{{ }^{1} \mathrm{H}\right\}$ at $100 \mathrm{MHz}$ ). The chemical shifts are reported in $\delta(\mathrm{ppm})$ and referenced to the residual proton and carbon signals $7.24 \mathrm{ppm}$ and $77.0 \mathrm{ppm}$ respectively of $\mathrm{CDCl}_{3}$ NMR solvent.

\subsection{Catalysis}

2.2.1 General procedure for ethylene oligomerisation reactions. In a typical experiment, a $500 \mathrm{~mL}$ steel autoclave was heated under vacuum for $2 \mathrm{~h}$ at $160^{\circ} \mathrm{C}$ and allowed to cool to the required temperature. The appropriate solution of the catalyst precursor for each reaction was first introduced into the reactor and the reaction mixture saturated with ethylene at 1 bar for $5 \mathrm{~min}$ and ethylene vented off. The co-catalyst, $\mathrm{EtAlCl}_{2}$ was added to the reaction mixture via a cannula. The reactor was then saturated with ethylene to the desired pressure and stirred at the required temperature and time. The ethylene pressure was maintained throughout the reaction. The reaction was stopped by turning off ethylene feed and connecting the reactor to two traps cooled with liquid nitrogen, followed by venting off the reactor. The reactor contents were isolated and quenched with $10 \% \mathrm{HCl}$ in methanol, and the product sampled for gaschromatography (GC) and gas-chromatography-mass spectrometry (GC-MS) analyses. The solvent from the remaining product was removed in vacuo and the mass of the product determined.

\subsection{Electrochemical methods}

The electrochemical cell consists of a three-electrode cell, which involved a glassy carbon (geometric area $=0.071 \mathrm{~cm}^{2}$ ) as a working electrode, $\mathrm{Ag} / \mathrm{AgCl}(3 \mathrm{M} \mathrm{KCl})$ reference electrode, and platinum wire as the counter electrode. The measurement was performed using a concentration of $1.0 \mathrm{mM}$ samples, in the presence of $0.1 \mathrm{M}$ tetra-butyl ammonium tetrafluoroborate $\left(\left[{ }^{t} \mathrm{BuN}\right]\left[\mathrm{BF}_{4}\right]\right)$ (supporting electrolyte) in dry DMF under argon atmosphere at room temperature. The glassy carbon electrode was polished on a Buehler-felt pad using alumina $(0.05 \mu \mathrm{m})$ and then washed with millipore water, sonicated for $5 \mathrm{~min}$ in millipore water and finally rinsed with $\mathrm{pH} 9.2$ buffer solution. This was done to ensure that there are no contaminants on the electrode surface before the electrochemical measurements. Argon was bubbled through the solution before recording the cyclic voltammogram to ensure an oxygen free solution.

\subsection{Molecular modelling method}

Modelling programs Spartan 08 V1.2.0 and Spartan 10.1.10 (ref. 18) were used for all calculations at the DFT B3LYP level of theory. The B3LYP functional level of theory is a Hartree-Fock DFT hybrid. However, the LACVP* basis set is a relativistic effective core-potential or pseudo potential that describes the atoms $\mathrm{H}-\mathrm{Ar}$ and transition metals with the $6-31 \mathrm{G}^{*}$ basis. The LANL2DZ basis set was used to model heavier atoms which make use of all-electron valence double zeta basis set D95V, done by Dunning, for first row elements ${ }^{19}$ and the Los Alamos 
ECP plus double zeta basis set for the atoms $\mathrm{Na}-\mathrm{La}, \mathrm{Hf}-\mathrm{Bi}^{20}$ done by Wadt and Hay. Spartan's graphical model builder and minimised which interact with the SYBYL force field ${ }^{\mathbf{2 1}}$ were used to construct the starting geometries of the molecular systems. All geometries were fully optimised without any symmetry constraints. Equilibrium geometries were characterised by the absence of imaginary frequencies, which also gave the HOMO, LUMO and charge density values. The transition state structures were with only one imaginary frequency and located without constrains using fully optimised standard transition state optimisation procedure in Spartan.

\section{Results and discussions}

\subsection{Catalysis}

3.1.1 Ethylene oligomerisation or polymerisation reactions using pre-catalysts 1-4. The ethylene catalysis of pre-catalysts 510 have been reported in literature by us. ${ }^{17 \boldsymbol{b}, \boldsymbol{c}}$ We report here the extensive catalytic activity of pre-catalysts 1-4.

The ethylene oligomerisation or polymerisation reactions for pre-catalysts 1-4 were investigated. Pre-catalyst $\mathbf{1}$ was used as a basis to investigate the optimum co-catalyst ratio and precatalyst loading needed for the polymerization reaction in hexane. The co-catalyst used is $\mathrm{EtAlCl}_{2}$, whiles the $\mathrm{Al}: \mathrm{Pd}$ ratio was varied from $100: 1$ to $200: 1$. This led to an increase in both the activity of the catalyst and molecular weights of the polyethylene produced. However, increasing in the ratio above 200 : 1 was followed by a drastic decrease in both activity and molecular weight. The decrease in molecular weight on increasing the $\mathrm{Al}: \mathrm{Pd}$ ratio is an indication of high chain transfer from the palladium species to the aluminium cocatalyst and fast chain termination, this in line with what is reported in the literature. ${ }^{22}$

The effect of catalyst loading of pre-catalyst $\mathbf{1}$ was also investigated. It was observed that increasing the pre-catalyst loading from $4 \mu \mathrm{mol}$ to $5 \mu \mathrm{mol}$ resulted in an increase in activity from $200 \mathrm{~kg} \mathrm{~mol} \mathrm{Pd}^{-1} \mathrm{~h}^{-1}$ to $262 \mathrm{~kg} \mathrm{~mol} \mathrm{Pd}^{-1} \mathrm{~h}^{-1}$. A further increase in pre-catalyst amount to $10 \mu \mathrm{mol}$, caused the

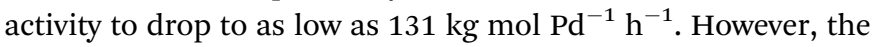
molecular weight of the polymer remained unchanged. A similar observation has been reported by Junges et $a .^{23}$ for a tridentate pyrazolyl $\mathrm{Cr}(\mathrm{III})$ pre-catalyst. In this system, a precatalyst loading of $10 \mu \mathrm{mol}$ gave a TOF of $66200 \mathrm{~h}^{-1}$ but at 30 $\mu$ mol loading reduces the TOF to $29000 \mathrm{~h}^{-1}$. Junges et al. attributed this to the ease at which the pre-catalyst solubilised in the reaction solvent at low pre-catalyst loading and catalyst aggregation at high pre-catalyst loading.

The optimum $\mathrm{Al}: \mathrm{Pd}$ ratio was 200:1 and pre-catalyst loading of $5 \mu \mathrm{mol}$ was established. Further catalytic investigations were performed in ethylene oligomerisation and polymerisation reactions using $\mathrm{EtAlCl}_{2}$ as co-catalyst (Scheme 1). At these optimum conditions other reaction parameters such as ethylene pressure, temperature, solvent and time were investigated.

The oligomerisation reaction was not exothermic, as there was no temperature increase during the reaction. All the precatalysts show moderate activities as ethylene oligomerisation

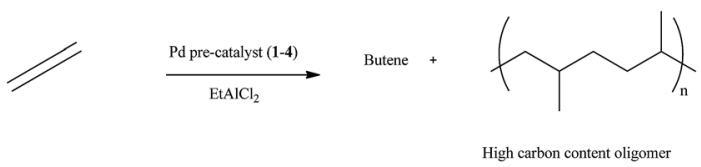

Scheme 1 Oligomerisation of ethylene catalysed by pre-catalyst 1-4 with $\mathrm{EtAlCl}_{2}$.

catalysts to produce mostly butene and higher chain oligomers. A typical GC (Fig. S1 $\dagger$ ) shows the presence of butene, which is 1butene but did not show the presence of higher oligomers. However, the product obtained after removing the solvent was a viscous liquid, which was initially suspected to be a low molecular weight polymer. GPC analyses were performed on these liquid products, their molecular weights were found to be lower than $1000 \mathrm{Da}$. Using Atmospheric pressure chemical ionization (APCI) a soft ionization technique, the molecular weights observed were between 267.0 and 623.0, an indication that the viscous liquid products are oligomers of ethylene. This technique gave an envelope shape spectra, indicating a single active catalytic species present upon activation with $\mathrm{EtAlCl}_{2} \mathrm{CO}-$ catalyst. A typical spectrum of the APCI is shown in Fig. S2. $\dagger$ An expanded form of the spectrum which shows isotopic distributions is presented in Fig. S3. $\dagger$ The difference between the isotopic patterns is $\mathbf{1 4 . 0 1 5 7}$ which correspond to a methylene group, indicating fragmentation of the oligomer chain.

${ }^{1} \mathrm{H}$ NMR spectrum (Fig. S4 $\dagger$ ) shows an olefinic group that support the low molecular weight of the ethylene oligomer produced. The olefinic group, appearing at $5.21 \mathrm{ppm}$ is a vinylene group ( $E$ and $Z \mathrm{R}^{1} \mathrm{CH}=\mathrm{CHR}^{2}$ ). The peaks appearing between $0.80 \mathrm{ppm}$ and $2.10 \mathrm{ppm}$ are different protons from $\mathrm{CH}_{2}$ and $\mathrm{CH}_{3}$ groups indicating that the products obtained in the catalytic reactions are ethylene oligomers.

3.1.2 Effect of catalyst structure on the catalytic activity. Among the six pre-catalysts investigated pre-catalyst 1 was found to be the most active (Table 1: entries 1-6). It appears the nature of the ligands play a significant role in the catalyst activity and the molecular weight of the ethylene oligomers. Precatalysts $\mathbf{1}$ and $\mathbf{2}$ that have pyrazolyl-pyridyl donor groups were more active and produced polymers with the highest molecular weights compared to $\mathbf{3}$ and $\mathbf{4}$ that have pyrazolyl-amine donor groups. For instance, under the same reaction conditions, the best activity for the pre-catalyst containing pyrazolyl-pyridyl

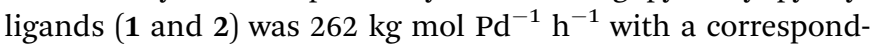
ing molecular weight of 507.0 for 1 . The activity for pre-catalyst

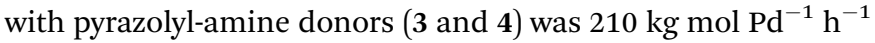
with 401.0 molecular weight for 3 . The high activities of precatalysts 1 and 2 compared to 3 and 4 could be due to the stable pre-catalysts formed by the strong donor ability of the pyridyl unit. Also pre-catalysts $\mathbf{1}$ and $\mathbf{3}$ that show high activities compared to 2 and 4 . These have no substituent in position 3 of the pyrazolyl unit. This is an indication that steric factors play a crucial role in the activity of these pre-catalysts. Due to the high catalytic activity of pre-catalyst $\mathbf{1}$, it was used in further studies on various catalytic reaction parameters.

Kinetically, the rate of oligomerisation or polymerisation increases with increase in ethylene pressure. ${ }^{24}$ The activity of 
Table 1 Ethylene oligomerisation reaction using pre-catalysts $1-4$ and $\mathrm{EtAlCl}_{2}$ as co-catalyst ${ }^{a}$

\begin{tabular}{|c|c|c|c|c|c|c|c|}
\hline Entry & Catalyst & Pressure (bar) & Yield $^{d}(\mathrm{~g})$ & Activity $\left(\mathrm{kg} \mathrm{mol} \mathrm{Pd}^{-1} \mathrm{~h}^{-1}\right)$ & Temperature $\left({ }^{\circ} \mathrm{C}\right)$ & Time (min) & Oligomer weight $^{e}(\mathrm{~m} / \mathrm{z})$ \\
\hline 3 & 1 & 10 & 1.31 & 262 & 25 & 60 & 507.0 \\
\hline 4 & 2 & 10 & 1.05 & 210 & 25 & 60 & 425.0 \\
\hline 6 & 4 & 10 & 0.65 & 130 & 25 & 60 & 345.0 \\
\hline 7 & 1 & 5 & 0.66 & 132 & 25 & 60 & 301.0 \\
\hline 8 & 1 & 20 & 1.41 & 282 & 25 & 60 & 511.0 \\
\hline 11 & 1 & 10 & 0.61 & 122 & 50 & 60 & 243.0 \\
\hline 12 & 1 & 10 & 0.56 & 112 & 60 & 60 & 220.0 \\
\hline 13 & $\mathbf{1}^{b}$ & 10 & 1.65 & 330 & 25 & 60 & - \\
\hline 14 & $\mathbf{1}^{c}$ & 10 & 1.81 & 362 & 25 & 60 & 623.0 \\
\hline 15 & 1 & 10 & 1.46 & 146 & 25 & 120 & 512.0 \\
\hline 16 & 1 & 10 & 1.58 & 105 & 25 & 180 & 519.0 \\
\hline
\end{tabular}

${ }^{a}$ Conditions: $6.0 \mathrm{~mL}$ of hexane. ${ }^{b}$ Toluene used as reaction solvent. ${ }^{c}$ Chlorobenzene used as reaction solvent; catalyst loading $=5 \mu \mathrm{mol} ; \mathrm{Al}: \mathrm{Pd}=$ $200: 1{ }^{d}$ Determined by mass difference of $70.0 \mathrm{~mL}$ hexane $(45.8 \mathrm{~g})$, toluene $(60.9 \mathrm{~g})$ or chlorobenzene $(77.7 \mathrm{~g})$ and mass of final solution. ${ }^{e}$ Determined by APCI.

pre-catalyst 1 and molecular weight of the ethylene oligomers produced showed marginal increment with increase in pressure. As an illustration, increasing the pressure from 10 bar to 30 bar saw only $0.10 \mathrm{~g}$ and $0.25 \mathrm{~g}$ increase from $1.31 \mathrm{~g}$ of products formed and also slight increase in activity (Table 1: entries 3, 8 and 9). A similar trend was observed for the molecular weights recorded. Where pressure is increased from 10 bar to 30 bar resulted in molecular weight of 507.0, 511.0 and 520.0 respectively (Table 1: entries 3, 8 and 9). The marginal increase in both mass and molecular weight as pressure was increased could be due to catalyst saturation.

Temperature variation affects the activity of the catalysts and molecular weight of the polymer obtained. For example an increase in temperature from $25{ }^{\circ} \mathrm{C}$ to $60{ }^{\circ} \mathrm{C}$ resulted in

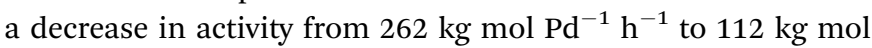
$\mathrm{Pd}^{-1} \mathrm{~h}^{-1}$ (Table 1: entries 3, 10-12). This can be attributed to decomposition or deactivation of the active species as well as lower ethylene solubility in the reaction solution at high temperatures. $^{25}$ The decrease in molecular weight could be due to faster chain termination than chain propagation at elevated temperature. $^{26}$

The reaction solvent was also varied by using hexane, toluene and chlorobenzene respectively. An increase in activity is observed which can be attributed to solubility of the active species (Table 1: entries 3,13 and 14). The results show that the active species is more soluble in a polar solvent, hence the observed increase in activity in the order hexane $<$ toluene $<$ chlorobenzene. Butene and liquid polyethylene were obtained when hexane and chlorobenzene were used as reaction solvent. The higher molecular weight of 623.0 was obtained for the oligomer using chlorobenzene, compared to 507.0 obtained for the reaction in hexane under the similar reaction conditions. In toluene, the products obtained were butene, ethyltoluene, mono-butyltoluenes and di-butyltoluenes (Fig. S5†). The alkyltoluenes are produced via Friedel-Crafts alkylation reaction. ${ }^{27}$ The oligomerisation reactions performed in toluene resulted in alkylation of the solvent with the oligomer produced and the ethylene. There was no clear evidence of triple alkylation of toluene from the GC data (Fig. S5 $\dagger$ ); suggesting that alkylation is more facile for butyltoluenes compared to ethyltoluenes.

Time run experiments were performed to establish the life time of the active species. Increasing the time $60 \mathrm{~min}$ to $180 \mathrm{~min}$ saw only a marginal increase in catalytic activity and molecular weight (Table 1: entries 15 and 16). After 60 min catalytic activity was low towards polymerization. The low activity recorded with longer reaction time indicates catalyst deactivate with time.

The following sections deal with extensive report on the determination of the electronic properties of the ligands and the complexes using $\mathrm{CV}$ and computational modelling.

\subsection{Electrochemical studies}

3.2.1 Electrochemical properties of compounds L1-L7. At a given temperature, the half-wave potential $\left(E_{1 / 2}\right)$ values change considerably for different solvents. The half-wave potential shifts toward more positive potentials in the order: DMSO < DMA $<$ NMF $<$ DMF $<$ ACN $<$ PEN $<$ ACE $<$ DCM. This order

Table 2 Cyclic voltammetry data for compounds L1-L7 ${ }^{a}$

\begin{tabular}{lllcl}
\hline Entry & Compound & $E_{1 / 2}(\mathrm{mV})$ & $\Delta E(\mathrm{mV})$ & $I_{\mathrm{pc}} / I_{\mathrm{pa}}$ \\
\hline 1 & Fc & 483.0 & 84.0 & 0.85 \\
2 & L1 & 335.0 & 97.0 & 0.72 \\
3 & L2 & 362.0 & 101.0 & 0.75 \\
4 & L3 & 325.0 & 83.0 & 0.63 \\
5 & L4 & 329.0 & 97.0 & 0.74 \\
6 & L5 & 357.0 & 86.0 & 0.72 \\
7 & L6 & 332.0 & 87.0 & 0.68 \\
8 & L7 & 633.0 & 155.0 & 0.12
\end{tabular}

${ }^{a}$ Conditions: solvent $=N, N$-dimethyl formamide (DMF); supporting electrolyte $=$ tetra- $n$-butylammonium-tetrafluoroborate $\left[{ }^{t} \mathrm{BuN}\right]\left[\mathrm{BF}_{4}\right]$; compound concentration $=1 \mathrm{mM}$; supporting electrolyte concentration $=0.1 \mathrm{M}$. Reference electrode $=\mathrm{Ag} / \mathrm{AgCl}$; counter electrode $=$ platinum wire; working electrode $=$ glassy carbon; $\mathbf{F c}=$ ferrocene, scan rate of $100 \mathrm{mV} \mathrm{s}^{-1} . \mathbf{F c}=$ ferrocene. 
<smiles>[R]c1cc([R])[nH]n1</smiles><smiles>[R]c1cc([12F])nn1Cc1ccccn1</smiles><smiles>[R]c1cc([R])n(CCN)n1</smiles><smiles>CC(=O)CC(C)=O</smiles>

Fig. 1 Ferrocenylpyrazolyl compounds L1-L7.

indicates that the oxidation of ferrocene to the ferrocenium is more difficult with decreasing polarity. ${ }^{28}$ The ferrocenium is more sensitive to interactions with the solvent molecules than ferrocene. Therefore, the strength of the interactions of the ferrocenium (which acts as a Lewis electron-pair acceptor) with solvent molecules (Lewis electron-pair donor) is expected to affect the oxidation of ferrocene and thus the half-wave potential. ${ }^{29}$ Based on the above hypothesis, $N, N$-dimethyl formamide (DMF) which is midway through the series was chosen as solvent for the cyclic voltammetry experiment.

The electrochemical properties of ligands L1-L7 and palladium(II) and nickel(II) complexes 1-10 were investigated by cyclic voltammetry in DMF with $0.1 \mathrm{M}\left[{ }^{t} \mathrm{BuN}^{\mathrm{B}}\right]\left[\mathrm{BF}_{4}\right]$ as supporting electrolyte. Table 2 summarises the redox potential data for compounds L1-L7 investigated (Fig. 1).

The cyclic voltammograms of compounds $\mathbf{L} 1$ and $\mathbf{L} 2$ showed a quasi-reversible peak corresponding to one electron transfer. The typical voltammogram for $\mathbf{L 2}$ is shown in Fig. 3. $\mathrm{Fe}^{\mathrm{II}}-\mathrm{Fe}^{\mathrm{III}}$ redox couples of the ferrocenyl unit of $\mathbf{L 1}$ and $\mathbf{L} 2$ showed $E_{1 / 2}$ at $335 \mathrm{mV}\left(\Delta E=97 \mathrm{mV}\right.$, and $\left.I_{\mathrm{pc}} / I_{\mathrm{pa}}=0.72\right)$ and $362 \mathrm{mV}(\Delta E=$ $101 \mathrm{mV}$ and $I_{\mathrm{pc}} / I_{\mathrm{pa}}=0.75$ ) respectively (Table 2: entries 2 and 3). The observed redox potentials are in agreement with the electron donor abilities of the pyrazolyl unit, which donates more electron density to the ferrocene moiety; and hence favouring the ease of oxidation of the ferrocenyl unit. ${ }^{30}$ Modification of $\mathbf{L 1}$
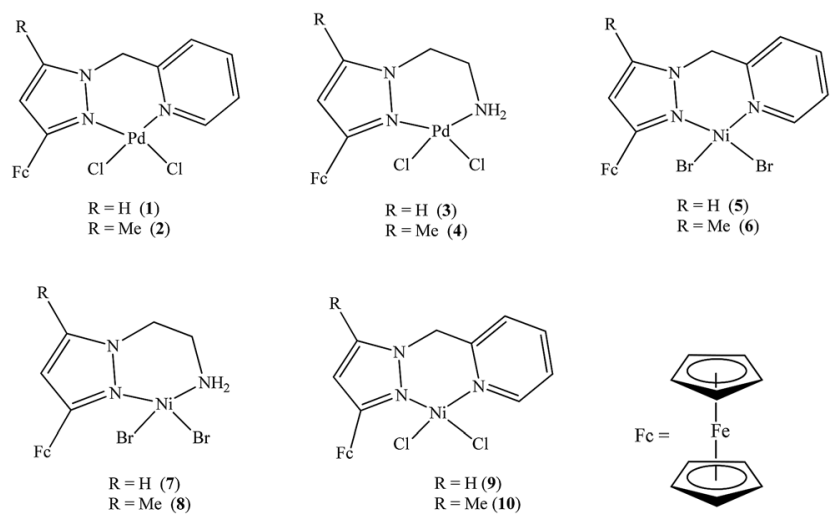

Fig. 2 Ferrocenylpyrazolyl palladium and nickel complexes 1-10.

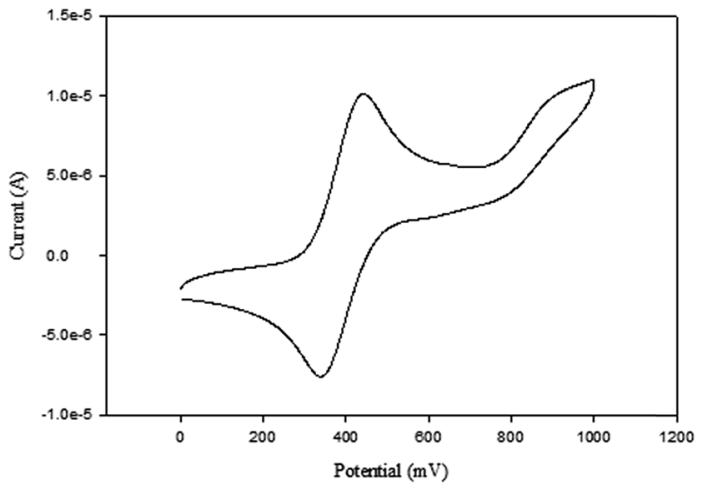

Fig. 3 Cyclic voltammogram of compound L2 in DMF, [ $\left.{ }^{t} B u N\right]\left[B_{4}\right]$ as supporting electrolyte, $\mathrm{Ag} / \mathrm{AgCl}$ as reference electrode, platinum wire as counter electrode, glassy carbon as working electrode, scan rate of $100 \mathrm{mV} \mathrm{s}^{-1}$, temperature $25^{\circ} \mathrm{C}$.

and $\mathbf{L} 2$ by introducing more electron donating groups such as methylene pyridine (L3 and L4) and ethylamine (L5 and L6) show significant improvement on the oxidation and still show quasi reversibility of the ferrocenyl unit (Table 2: entries 2, 3 and 4-7). However, L3 and L4 showed the oxidation of ferrocenyl unit is easier compared $\mathbf{L 5}$ and L6. This could be due to the aromatic nature of the pyridine ring which helps to form a partial conjugation system with the pyrazolyl unit. Compared to compounds containing ethylamine group, despite its electron donating ability, these ligands do not form a conjugated system; hence this has less oxidative influence compared to the methylene pyridine. The influence of substituent (either hydrogen or methyl) on the pyrazolyl moiety also appears to play a role in the oxidation of the ferrocenyl unit. In principle, the electron donating methyl substituents should enhance the ease of oxidation compare to hydrogen. Comparing the compounds which differ by either methyl or hydrogen on the pyrazolyl unit, only $\mathbf{L} 6$ undergoes easy oxidation compared to L5. Compounds L1, L2, L3 and L4 however, showed otherwise. As expected, compound $\mathbf{L} 7$ which has an electron withdrawing group shows one electron quasi-reversible oxidation peak (Fig. S6†) of the ferrocenyl unit with half wave potential of $633.0 \mathrm{mV}$ and $I_{\mathrm{pc}} / I_{\mathrm{pa}}$ value of 0.12 (Table 2 : entry 8 ).

A plot of current (A) against scan rate $\left(\mathrm{mV} \mathrm{s}^{-1}\right)$ show a linear relationship for all the compounds discussed above. The linear relationship suggests that the mechanisms of oxidation of the ferrocenyl unit in L1-L7 are diffusion controlled. A typical plot for $\mathbf{L} 2$ is shown in Fig. S7. $\uparrow$ The diffusion controlled mechanism indicates that there is a spontaneous transfer of the electroactive species from regions of higher concentrations to regions of lower concentrations.

The compounds also show that the half wave potentials are independent of scan rates. An example is given in Fig. S8, $\dagger$ which shows half wave potentials are independent of scan rates for compound L2. This also demonstrates that the diffusion controlled process occurs quickly, and the rate of reaction is controlled by rate of transport of the reactants through the medium. 
Table 3 Cyclic voltammetry data for complexes $1-10^{a}$

\begin{tabular}{lllllll}
\hline Entry & Compound & $E_{1 / 2}(\mathrm{mV})$ & $\Delta E(\mathrm{mV})$ & $I_{\mathrm{pc}} / I_{\mathrm{pa}}$ & $K_{\mathrm{c}}$ & Yield \\
\hline 1 & $\mathbf{1}$ & 456.0 & 118.0 & 0.44 & - & 1.31 \\
2 & $\mathbf{2}$ & 412.0 & 104.0 & 0.46 & - & 1.05 \\
3 & $\mathbf{3}$ & 423.0 & 120 & 0.40 & - & 0.98 \\
4 & $\mathbf{4}$ & 410.0 & 115 & 0.48 & - & 0.65 \\
5 & $\mathbf{5}$ & 425.0 & 92.0 & 0.46 & 589 & $17.80^{b}$ \\
6 & $\mathbf{6}$ & 393.0 & 95.0 & 0.49 & 613 & $10.20^{b}$ \\
7 & 7 & 436.0 & 83.0 & 0.49 & 130 & $6.70^{b}$ \\
8 & $\mathbf{8}$ & 433.0 & 77.0 & 0.72 & 170 & $5.80^{b}$ \\
9 & $\mathbf{9}$ & 417.0 & 81.0 & 0.50 & 520 & $8.20^{b}$ \\
10 & $\mathbf{1 0}$ & 424.0 & 95.0 & 0.35 & 592 & $7.10^{b}$
\end{tabular}

${ }^{a}$ Conditions: solvent $=N, N$-dimethyl formamide (DMF); supporting electrolyte $=$ tetra- $n$-butylammonium-tetrafluoroborate $\left[{ }^{t} \mathrm{BuN}\right]\left[\mathrm{BF}_{4}\right]$; analyte concentration $=1 \mathrm{mM}$; supporting electrolyte concentration = $0.1 \mathrm{M}$. Reference electrode $=\mathrm{Ag} / \mathrm{AgCl}$; counter electrode $=$ platinum wire; working electrode $=$ glassy carbon, scan rate of $100 \mathrm{mV} \mathrm{s}^{-1}$. ${ }^{b}$ Published results from ref. $17 b$.

3.2.2 Electrochemical properties of complexes 1-10. Palladium complexes 1-4 showed redox potential for the ferrocenyl unit with higher $E_{1 / 2}$ values between 410 and $456 \mathrm{mV}$ (Table 3) compared to that of the corresponding ligands which are between 325 and $357 \mathrm{mV}$. Also, the observed $I_{\mathrm{pc}} / I_{\mathrm{pa}}$ values were between 0.40 and 0.49 , which is an indication of also quasireversible behaviour. This could be due to the dative covalent bonds which are formed between the palladium and the nitrogen donor atoms of the ligand. Therefore, electrons are donated from the ligand to the palladium metal centre, resulting in low electron density on the ferrocenyl moiety. Hence, the palladium complexes showed higher half wave potential for $\mathrm{Fe}^{\mathrm{II}} / \mathrm{Fe}^{\mathrm{III}}$ redox couple than their corresponding ligands. A typical voltammogram for complex 1 is shown in Fig. 4 . There is no evidence from the voltammogram of delocalisation of electrons between the two metal centres. In this voltammogram, the second wave potential is difficult to determine. This could suggest aggregation of the complexes or lack of interaction between the two metal centres.

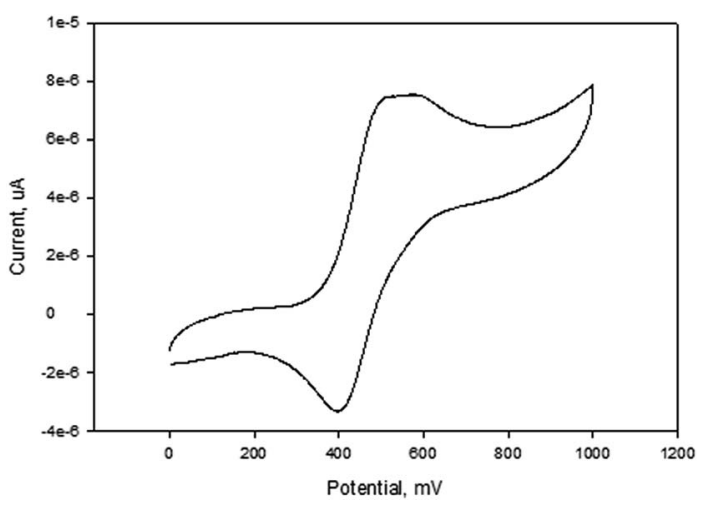

Fig. 4 Cyclic voltammogram of complex 1 in DMF, $\left[{ }^{t} B u N\right]\left[B_{4}\right]$ as supporting electrolyte, $\mathrm{Ag} / \mathrm{AgCl}$ as reference electrode, platinum wire as counter electrode, glassy carbon as working electrode, scan rate of $100 \mathrm{mV} \mathrm{s}^{-1}$, temperature $=25^{\circ} \mathrm{C}$.
$\mathrm{NiBr}_{2}$ or $\mathrm{NiCl}_{2}$ complexes of L1-L6 (5-10 (Fig. 2)) also showed redox oxidation potential of the ferrocenyl unit in the various ligands. The half wave potentials for these complexes were between 389 and $436 \mathrm{mV}$ and are higher than corresponding free ligands (Table 3). However, these half wave potentials are still lower compared to ferrocene $(483 \mathrm{mV})$. The $I_{\mathrm{pc}} / I_{\mathrm{pa}}$ values also show that the oxidation of these complexes are quasi-reversible. The voltammograms of the complexes show delocalisation of electron between the metal centres. A typical voltammogram showing delocalisation of electron is Fig. 5. The extent of electron exchange between the iron and nickel centres could be expressed by the comproportionation constant $\left(K_{\mathrm{c}}\right)$ using the Nernst equation. ${ }^{31}$

$$
K_{\mathrm{c}}=\exp (\Delta E) F / R T
$$

$\left(\Delta E=E_{2}-E_{1}, F=\right.$ Faraday constant, $R=$ gas constant, $T=$ temperature).

To compare the degree of interactions between the metal centres using their equilibrium constants, the Robin and Day classification scheme was used..$^{32}$ The Robin and Day classification scheme classifies molecules into three different classes. A class I molecule has the least amount of electronic interaction with a value $K_{\mathrm{c}}<10^{2}$. Class II molecules have moderate electronic interactions, ranging between $10^{2}$ and $10^{6}$. Class III molecules on the other hand have $K_{\mathrm{c}}>10^{6}$. Class III molecules have the best electron interactions. The degree of electronic interaction is directly related to the rate of the electron transfer i.e. large electronic interaction prefers fast electron transfer rates, while small electronic interaction depicts slow electron transfer rates.

The comproportionation constants $K_{\mathrm{c}}$ for complexes 5-10 (Table 3) suggests moderate delocalisation of electrons between the two metal centres. Complexes 7 and 8 recorded the lowest comproportionation constants, compared to 5, 6, 9 and $\mathbf{1 0 ,}$ which could be due to the non-aromatic nature of the ligands, hence reducing the extent of electron transfer through conjugation. Complexes 5-10 therefore can be classified under the class II, according to the Robin and Day classification scheme.

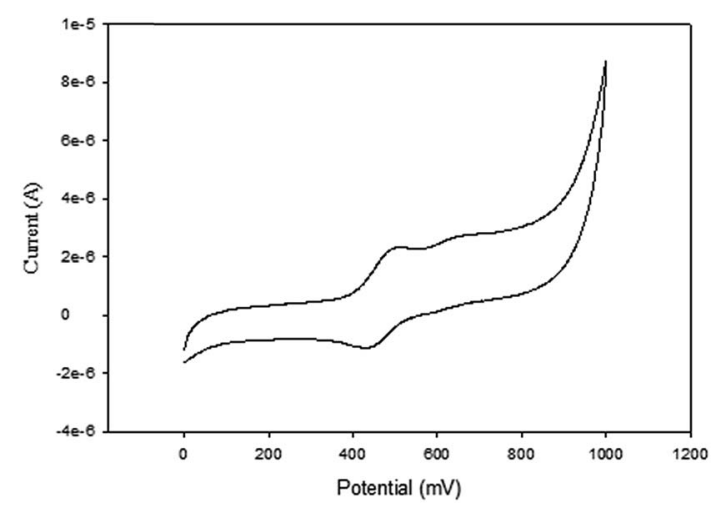

Fig. 5 Cyclic voltammogram of complex 6 in DMF, $\left[{ }^{t} B u N\right]\left[B_{4}\right]$ as supporting electrolyte, $\mathrm{Ag} / \mathrm{AgCl}$ as reference electrode, platinum wire as counter electrode, glassy carbon as working electrode, scan rate of $100 \mathrm{mV} \mathrm{s}^{-1}$, temperature $25^{\circ} \mathrm{C}$. 
The higher the half wave potential the more electrophilic the metal centres it is associated with. This indicates that the higher the half wave potential for $\mathrm{Fe}^{\mathrm{II}} / \mathrm{Fe}^{\mathrm{III}}$ redox couple, the difficult will it be to oxidise the ferrocenyl unit due to the withdrawal of electron density by nickel(II) or palladium(II) unit. In this way, we used ferrocene as a sensor to probe the electrophilic nature of both the nickel and palladium complexes. We have also correlated the electrophilicity of the nickel or palladium centre with their catalytic activities.

With the same ligand system, there is a direct correlation between the electrophilicity of the metal centre and yield. For example Table 3, entries 1-8, higher yields are associated with lower $E_{1 / 2}$ values. In addition, Table 3, entries 5 and 9, with different halide substituents but the same metal and ligand environment, a similar relationship is observed. The nickel complexes generally have higher yields compared to palladium complexes and it is associated with lower $E_{1 / 2}$ values. For example, in Table 3, entries 1 and 9, the nickel complex shows a higher yield compared to the palladium analogue. However, a similar observation was not made for entries 2 and 10. Other factors in addition to the electrophilicity of the metal centre are responsible for the high activities of the complexes. Other factors, such as solubility and stability of the active species can also play roles in the activities of these catalysts.

To further investigate the effect of the electrophilicity of the metal centre on activity and yield, molecular modeling was carried out.

\subsection{Molecular modeling of ligands and complexes}

3.3.1 Electronic properties of ligands L1-L6. To investigate the electronic properties of these ligands; $\varepsilon_{\mathrm{HOMO}}, \varepsilon_{\mathrm{LUMO}}$, and global descriptors such as chemical potential $(\mu)$, chemical hardness $(\eta)$ and electrophilicity $(\omega)$ were calculated according to the method used by Thanikaivelan et $a l .{ }^{33}$ These descriptors are important electronic features used to describe stability, reactivity and other related properties of molecules. ${ }^{34}$ These descriptors were determined from HOMO and LUMO energies using the equations:

$$
\begin{gathered}
\mu=\frac{\varepsilon_{\mathrm{LUMO}}+\varepsilon_{\mathrm{HOMO}}}{2} \\
\eta=\frac{\varepsilon_{\mathrm{LUMO}}-\varepsilon_{\mathrm{HOMO}}}{2} \\
\omega=\frac{\mu^{2}}{2 \eta}
\end{gathered}
$$

Generally, the HOMO of a ligand provides information about electron donating ability while the LUMO gives the electron accepting capability. Therefore, to understand the nature of the donor-acceptor behaviour the shape of the HOMO and LUMO can be used.

Fig. S9† shows that the HOMO of both $\mathbf{L 1}$ and $\mathbf{L} 4$ are localized on both the pyrazolyl nitrogen and the iron of the ferrocenyl unit. The localization of the HOMO on the pyrazolyl nitrogen atom is in agreement with the formation of $\sigma$-bond through that nitrogen atom to a metal. The HOMO of the iron metal is an indication of a possible transfer of the electron density to the pyrazolyl unit during the complex formation. The LUMO also shows localization on the pyridyl unit, which is an indication of potential $\pi$-acceptor behaviours of this arm of the ligand. However, L1 shows localization in the whole ligand system also suggesting that this ligand has $\pi$-acceptor potential. The strength of $\pi$-acceptor potential is determined by the more negative value of $\varepsilon_{\text {LUMO }}$. Table 4 shows the values for $\varepsilon_{\text {LUMO }}$ for ligands L1-L6. The values show that the ligands containing pyridyl unit have more electron accepting capabilities compared to the rest (Table 4: entries 3 and 4). This is followed by the aliphatic amines (Table 4 : entries 5 and 6) then the pyrazolyl ligands (Table 4: entries 1 and 2).

To confirm further the $\pi$-accepting nature of these ligands, the electrophilicity index of each ligand was determined (Table 4). The higher the electrophilicity index the more electrophilic the compound. The data shows that the pyridyl ligands are more electrophilic than the ligands containing aliphatic amines, which are in turn more electrophilic than to the pyrazolyl ligands. Furthermore the ligands with hydrogen at the 3 position of the pyrazolyl unit are more electrophilic compared to the methyl substituted ligands.

Determination of the electronic properties of the complexes 1-8. The activity of metal pre-catalyst for olefin oligomerisation or polymerisation reactions, depend strongly on the nature of the ligands surrounding the metal. The nature of ligands in fact influences the electrophilicity of the metal centre. A highly electrophilic metal pre-catalyst, is expected to be highly active because the olefin is electron rich and therefore can readily coordinate to a more electrophilic metal centre.

HOMO-LUMO gap, global descriptors (chemical hardness $(\eta)$ and electrophilicity $(\omega))$ and charge density are the parameters considered in predicting the electrophilicity of the metal centres of these complexes.

3.3.2 HOMO-LUMO gap. The HOMO-LUMO gap of a metal complex shows the direction of flow of electrons. Since the HOMOs are predominantly occupied by d-orbital electrons, smaller HOMO-LUMO gap will facilitate $\pi$-back donation of electrons from the metal to the ligand system and hence the metal centre will be electrophilic. The calculations performed on complexes 1-8 (Table 4; entries 7-14) show that the gaps for the palladium complexes are larger compared to the nickel complexes. This suggests that the nickel centres are more electrophilic compared to the palladium. Among the palladium complexes 1 (Table 4: entry 7) has the least gap while for the nickel complex 5 recorded the smallest gap (Table 4: entry 11). The results correspond to the experimental results where $\mathbf{1}$ and 5 were the most active among their respective complexes. Typical diagrams of the HOMO-LUMO gaps of complexes 2 and 6 are shown in Fig. S10 and S11. $\dagger$ It is therefore expected that the nickel complexes would be more active compared to the palladium complexes for olefin oligomerisation or polymerisation reactions. This is confirmed by experimental observations. The palladium complex 1 when activated with $\mathrm{EtAlCl}_{2}$ in the 
Table 4 Data of global descriptors; chemical potential $(\mu)$, chemical hardness $(\eta)$ and electrophilicity $(\omega)$ using B3LYP level of theory and LACVP* basis set for L1-L6 and 1-8

\begin{tabular}{|c|c|c|c|c|c|c|c|}
\hline Entry & Compound & $\varepsilon_{\text {номо }}(\mathrm{eV})$ & $\varepsilon_{\text {LUMO }}(\mathrm{eV})$ & $\mu(\mathrm{eV})$ & $\eta(\mathrm{eV})$ & $\omega(\mathrm{eV})$ & Yield $(\mathrm{g})$ \\
\hline 1 & L1 & -5.15 & -0.17 & -2.66 & 2.49 & 1.42 & \\
\hline 2 & $\mathbf{L} 2$ & -4.97 & 0.03 & -2.47 & 2.50 & 1.22 & \\
\hline 4 & $\mathbf{L 4}$ & -5.12 & -0.77 & -2.95 & 2.18 & 1.99 & \\
\hline 5 & L5 & -5.14 & -0.65 & -2.92 & 2.23 & 1.91 & \\
\hline 6 & L6 & -5.09 & -0.69 & -2.89 & 2.20 & 1.89 & \\
\hline 9 & 3 & -5.28 & -2.14 & -3.71 & 1.57 & 4.38 & 0.98 \\
\hline 10 & 4 & -5.87 & -2.12 & -3.99 & 1.88 & 4.23 & 0.65 \\
\hline 11 & 5 & -5.25 & -3.47 & -4.36 & 0.89 & 10.68 & $17.80^{a}$ \\
\hline 12 & 6 & -5.23 & -3.39 & -4.31 & 0.92 & 10.10 & $10.20^{a}$ \\
\hline 13 & 7 & -5.30 & -3.23 & -4.27 & 1.04 & 8.77 & $6.70^{a}$ \\
\hline 14 & 8 & -5.41 & -3.21 & -4.31 & 1.10 & 8.44 & $5.80^{a}$ \\
\hline
\end{tabular}

presence of ethylene shows an activity of $362 \mathrm{~kg} \mathrm{~mol} \mathrm{Pd}{ }^{-1} \mathrm{~h}^{-1}$ whereas the nickel complex 5 shows activity of $1776 \mathrm{~kg} \mathrm{~mol} \mathrm{Ni}^{-1}$ $\mathrm{h}^{-1}$ under similar conditions. ${ }^{\mathbf{1 7 b}}$

\subsection{Determination of the electronic properties of 1-8 using global descriptors}

The global descriptors chemical hardness $(\eta)$ and electrophilicity $(\omega)$ were used to predict the electronic properties of 1-8.

3.4.1 Chemical hardness $(\boldsymbol{\eta})$. The chemical hardness $(\eta)$ of a complex is an electronic quantity which is used to characterise the relative stability and the resistance to changes in the number of electrons. ${ }^{35}$ The higher the value for the chemical hardness the more stable and less reactive. The data in Table 4 entries 11-14 show that the nickel complexes have chemical hardness values between 0.81 and $1.65 \mathrm{eV}$ which make them more reactive compare to the palladium complexes with values between 1.55 and $1.95 \mathrm{eV}$ (Table 4; entries 7-10). In order to find a correlation between the calculated chemical hardness of the complexes and observed catalytic yield, a graph of yield against calculated chemical hardness was plotted (Fig. 6 and 7). The graph for the palladium complexes (Fig. 6) shows a near linear

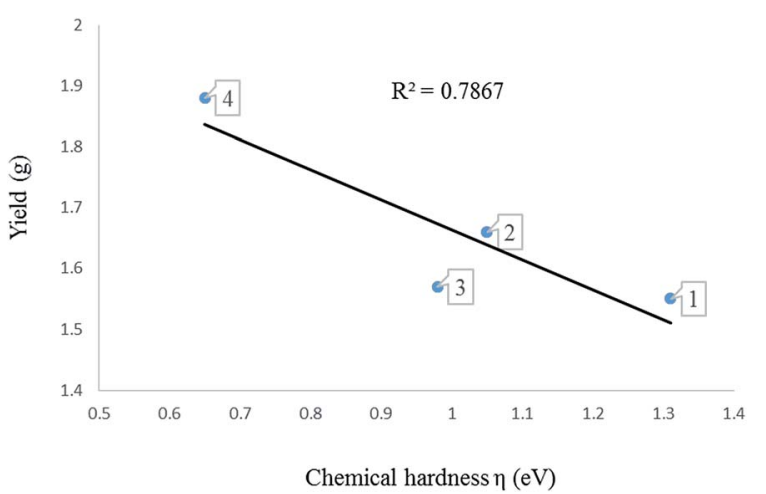

Fig. 6 A graph of chemical hardness against yield of oligomers produced using complexes $1-4$. fit with $R^{2}$ value of 0.7867 , indicating a correlation between these two parameters. The best yield was obtained when the chemical hardness was minimum $(1.55 \mathrm{eV})$ and the least yield was found at $1.88 \mathrm{eV}$. Similar observation was made for the nickel complexes (Fig. 7) where the $R^{2}$ value is 0.7654 was recorded.

3.4.2 Electrophilicity index $(\omega)$. A quantitative classification of the global electrophilic nature of the complex can be determined by the electrophilicity index. The higher the value of $\omega$, the more electrophilic the metal centre in the complex. Table 4 show that the nickel complexes are more electrophilic compared to the palladium complexes. To relate the catalytic yields of the complexes to electrophilicity index, a graph of electrophilicity index against yield were plotted as shown Fig. S12 and $\mathrm{S} 13 \dagger$ for palladium and nickel complexes respectively.

3.4.3 Charge density. The charge density of an atom or element shows the density of electrons located around the atom. The more positive the charge density the more electrophilic the atom or element is. The molecular modelling of the charge density for complexes 1-8 are presented in Table S2 $\uparrow$ respectively and the typical images of the charge densities for $\mathbf{1}$ and 6 drawn with isovalue of 1.0 are shown in Fig. S14 and S15. $\dagger$

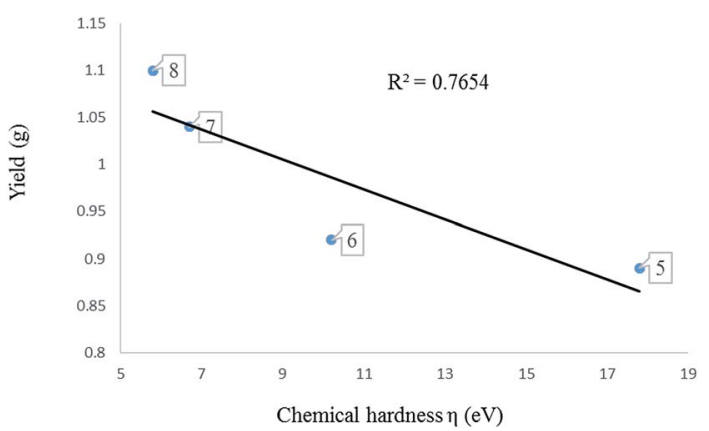

Fig. 7 A graph of chemical hardness against yield of oligomers produced using complexes 5-8. 
The electron density values for both the palladium and nickel complexes are in agreement with the prediction made with the HOMO-LUMO gap. The palladium centres are less positive compared to the nickel centres.

\section{Conclusion}

The palladium complexes were used as pre-catalysts for the oligomerisation of ethylene upon activation with $\mathrm{EtAlCl}_{2}$ to 1butene and higher carbon content oligomers, typically with 20 to 52 carbon atoms in the oligomer. The palladium pre-catalysts showed high activities in chlorobenzene for ethylene reactions than in hexane. In toluene, in addition to butene, ethyltoluenes and butyltoluenes were produced. The cyclic voltammetry studies show that ligands L1-L6 which have electron donating groups aid the ease of oxidation of the ferrocenyl moiety, while for L7 which has electron withdrawing group, oxidation of the ferrocenyl unit is difficult.

Cyclic voltammetry results for the nickel and palladium complexes show it is more difficult to oxidise the ferrocenyl unit in these ligands, indicating the electrophilic nature of both metals. A direct correlation between the electrophilicity of the metal is associated with a lower $E_{1 / 2}$ and yield within a similar ligand system.

Molecular modelling of the palladium and nickel complexes show singlet state species and these complexes are stable compared to their corresponding ligands, which is expected. Calculations of the electronic properties of the complexes show that electrophilicity of the metal centre correlate with the activity of the pre-catalysts, an indication of the role electrophilicity plays in the activity of the pre-catalysts. Molecular modelling show that the higher the electrophilicity of the metal centre the high the activity of the catalyst.

This study shows that CV and molecular modelling studies could be used as simple tool to predict activity of a catalyst.

\section{Conflicts of interest}

There are no conflicts to declare.

\section{Acknowledgements}

We acknowledge the National Research Foundation (South Africa) and the University of Johannesburg for financial support for this project.

\section{References}

1 M. Voith, M. McCoy, M. S. Reisch, A. H. Tullo and J. Tremblay, Chem. Eng. News, 2010, 88, 33-67.

2 Nexant, Process Evaluation Research Planning (PERP) ReportEthylene, 2009, 08/09-5.

3 Nexant, Process Evaluation Research Planning (PERP) ReportAlpha Olefins, 2008, 06/07-5.

4 (a) ed. P. Stepnicka, Ferrocenes: Ligands, Materials and Biomolecules, John Wiley \& Sons Ltd, Chichester, 2008; (b) ed. A. Togni and T. Hayashi, Ferrocenes: Homogeneous
Catalysis, Organic Synthesis, Material Science, $\mathrm{VCH}$ Verlagsgesellschaft, Weinheim, 1995.

5 A. R. Pike, L. C. Ryder, B. R. Horrocks, W. Clegg, B. A. Connolly and A. Houlton, Chem.-Eur. J., 2004, 11, 344-353.

6 F. Spanig, C. Kolvacs, F. Hauke, K. Ohlubo, F. Fukuzumi, D. M. Guldi and A. Hirsch, J. Am. Chem. Soc., 2009, 131, 8180-8195.

7 (a) D. Saravanakumar, N. Sengottuvelan, V. Narayanan, M. Kandaswamy and T. L. Varghese, J. Appl. Polym. Sci., 2011, 119, 2517-2524; (b) J. Conradie and J. C. Swarts, Organometallics, 2009, 28, 1018-1026; (c) Q. L. Shen, S. Shekhar, J. P. Stambuli and J. F. Hartwig, Angew. Chem., Int. Ed., 2005, 44, 1371-1375.

8 (a) D. E. Herbert, J. B. Gilroy, W. Y. Chan, L. Chabanne, A. Staubitz, A. J. Lough and I. Manners, J. Am. Chem. Soc., 2009, 131, 14958-14968; (b) Y. Yu, A. D. Bond, P. W. Leonard, U. J. Lorenz, T. V. Timofeeva, K. P. Vollhardt, G. Whitener and A. Yakovenko, Chem. Commun., 2006, 2572-2574; (c) A. K. Diallo, J. Ruiz and D. Astruc, Inorg. Chem., 2010, 49, 1913-1920.

9 V. A. Sauro and M. S. Workentin, Can. J. Chem., 2002, 80, 250-262.

10 V. C. Gibson and S. K. Spitzmesser, Chem. Rev., 2003, 103, 283-316.

11 T. Zhang, D. Guo, S. Jie, W.-H. Sun, T. Li and X. Yang, J. Polym. Sci., Part A: Polym. Chem., 2004, 04-42, 4765-4774.

12 (a) L. Deng, P. Margl and T. Ziegler, J. Am. Chem. Soc., 1999, 121, 6479-6487; (b) D. Guo, L. Han, T. Zhang, W.-H. Sun, T. Li and X. Yang, Macromol. Theory Simul., 2002, 11, 10061012.

13 P. C. Möhring and N. J. Coville, J. Mol. Catal., 1992, 77, 4150.

14 (a) D. Guo, X. Yang, L. Yang, T. Liu, Y. Li, H. Hong and Y. Hu, J. Polym. Sci., Part A: Polym. Chem., 2000, 38, 2232-2238; (b) D. Guo, X. Yang, T. Liu and Y. Hu, Macromol. Theory Simul., 2001, 10, 75-78.

15 D. Guo, L. Han, T. Zhang, W. Sun, T. Li and X. Yang, Macromol. Theory Simul., 2002, 11, 1006-1012.

16 (a) J. Ramos, V. Cruz, A. Munoz-Escalona and J. Martinezsalazar, Polymer, 2001, 42, 8019-8023; (b) J. Ramos, V. Cruz, A. Munoz-Escalona and J. Martinez-salazar, Polymer, 2003, 44, 2169-2176; (c) T. K. Woo, P. E. Blöchl and T. Ziegler, J. Phys. Chem. A, 2000, 104, 121-129; (d) D. G. Musaev, R. D. J. Froese, M. Svensson and K. Morokuma, J. Am. Chem. Soc., 1997, 119, 367-374; (e) S. Strömberg, K. Zetterberg and P. E. M. Sieghbahn, J. Chem. Soc., Dalton Trans., 1997, 4147.

17 (a) W. Bell, J. A. Crayston, C. Glidewell, M. A. Mazid and M. B. Hursthouse, J. Organomet. Chem., 1992, 434, 115121; (b) C. Obuah, J. H. L. Jordaan and J. Darkwa, Catal. Sci. Technol., 2016, 6, 4814-4823; (c) C. Obuah, A. Munyaneza, I. A. Guzei and J. Darkwa, Dalton Trans., 2014, 43, 8940-8950.

18 Spartan, Wavefunction, Inc., 18401 Von Karman Ave., \# 370, Irvine, CA, 92715, USA. 
19 T. H. Dunning Jr and P. J. Hay, Gaussian basis sets for molecular calculations, in Modern Theoretical Chemistry, ed. H. F. Schaefer III, Plenum, New York, 1976, vol. 3, pp. $1-28$.

20 (a) W. R. Wadt and P. J. Hay, J. Chem. Phys., 1985, 82, 270283; (b) W. R. Wadt and P. J. Hay, J. Chem. Phys., 1985, 82, 284-298; (c) W. R. Wadt and P. J. Hay, J. Chem. Phys., 1985, 82, 299-310.

21 M. Clark, R. D. Cramer and N. V. Opdenbosch, J. Comput. Chem., 1989, 10, 982-1012.

22 (a) Z. Huang, K. Song, F. Liu, J. Long, H. Hu, H. Gao and Q. Wu, J. Polym. Sci., Part A: Polym. Chem., 2008, 46, 16181628; (b) K. Tomov, V. C. Gibson, G. J. P. Britovsek, R. J. Long, M. van Meurs, D. J. Jones, K. P. Tellmann and J. J. Chirinos, Organometallics, 2009, 28, 7033-7040.

23 F. Junges, M. C. A. Kuhn, A. H. D. P. dos Santos, C. R. K. Rabello, C. M. Thomas, J.-F. Carpentier and O. L. Casagrande Jr, Organometallics, 2007, 26, 4010-4014.

24 (a) R. Walsh, D. H. Morgan, A. Bollmann and J. T. Dixon, Appl. Catal., A, 2006, 306, 184-191; (b) S. Kuhlmann, J. T. Dixon, M. Haumann, D. H. Morgan, J. Ofili, O. Spuhl, N. Taccardi and P. Wasserscheid, Adv. Synth. Catal., 2006, 348, 1200-1206.

25 G. J. P. Britovsek, M. Bruce, V. C. Gibson, B. S. Kimberley, P. J. Maddox, S. Mastroianni, S. J. McTavish, C. Redshaw, G. A. Solan, S. Strömberg, A. J. P. White and D. J. Williams, J. Am. Chem. Soc., 1999, 121, 8728-8740.

26 (a) S. D. Ittel, L. K. Johnson and M. Brookhart, Chem. Rev., 2000, 100, 1169-1203; (b) V. C. Gibson and S. K. Spitzmesser, Chem. Rev., 2003, 103, 283-315; (c) G. J. P. Britovsek, S. Mastronianni, V. C. Gibson, S. P. D. Baugh, C. Redshaw, G. A. Solan, A. J. P. White,
D. J. Williams and M. R. Elsegood, Chem.-Eur. J., 2000, 6, 2221-2231.

27 G. A. Olah, R. Khrisnamurti and G. K. S. Prakash, in Comprehensive Organic Synthesis, Pergamon, New York, 1st edn, 1991, Vol. 3, pp. 293-339.

28 (a) P. R. Sharp and K. G. Frank, Inorg. Chem., 1985, 24, 18081813; (b) S. M. Batterjee, M. I. Marzouk, M. E. Aazab and M. A. El-Hashash, Appl. Organomet. Chem., 2003, 17, 291297.

29 B. Keita, D. Bouaziz and L. Nadjo, J. Electrochem. Soc., 1988, 135, 87-91.

30 (a) K. N. Jayaprakash, P. C. Ray, I. Matsuoka, M. M. Bhadbhade, V. G. Puranike, P. K. Das, H. Nishihara and A. Sarkar, Organometallics, 1999, 18, 3851-3858; (b) P. Zanello, G. Opromolla, F. F. d. Biani, A. Ceccanti and G. Giorgi, Inorg. Chim. Acta, 1997, 255, 47-52; (c) B. Bildstein, M. Malaun, H. Kopacka, M. Fontani and P. Zanello, Inorg. Chim. Acta, 2000, 300, 16-22; (d) H. K. Sharma, K. H. Pannell, I. Ledoux, J. Zyss, A. Ceccanti and P. Zanello, Organometallics, 2000, 19, 770-774.

31 (a) L. Codognoto, P. G. Zanichelli and R. L. Sernaglia, J. Braz. Chem. Soc., 2005, 16, 620-625; (b) S. Denofre, Y. Gushikem, S. C. Castro and Y. Kawano, J. Chem. Soc., Faraday Trans., 1993, 89, 1057-1061.

32 M. B. Robin and P. Day, Adv. Inorg. Chem. Radiochem., 1967, 10, 247-422.

33 P. Thanikaivelan, V. Subramanian, R. J. Rao and B. U. Nair, Chem. Phys. Lett., 2000, 323, 59-70.

34 B. Hemmateenejad, M. Sanchooli and A. Mehdipour, J. Phys. Org. Chem., 2009, 22, 613-618.

35 X. B. Li, H. Y. Wang, R. Lv, W. D. Wu, J. S. Luo and Y. J. Tang, J. Phys. Chem. A, 2009, 113, 10335-10342. 